\title{
FREUD, AS NEUROCIÊNCIAS E UMA TEORIA DA MEMÓRIA ${ }^{1}$
}

\author{
Josiane Cristina Bocchi \\ Milena de Barros Viana
}

\begin{abstract}
Resumo: Alguns estudos têm demonstrado que conceitos psicanalíticos e observações neurocientíficas recentes podem ser complementares, contribuindo para um melhor entendimento de determinados processos psicobiológicos. Esses estudos também sugerem a possibilidade de interpretação de conceitos psicanalíticos a partir de sua aproximação com as neurociências. O presente trabalho investiga possíveis relações entre uma teoria da memória proposta por Freud e concepções neurocientíficas que surgem a partir da segunda metade do século XX,com base em observações clínicas (o caso do paciente H.M.) e experimentais (o conceito de potenciação de longa duração, LTP). Primeiramente, são apresentadas as ideias de Freud sobre processos mnemônicos que fundamentam a construção de um "Eu", da obra Projeto para uma psicologia científica (1950/1976). Posteriormente, as principais observações que subsidiaram a construção de uma teoria neurobiológica sobre a memória são analisadas. Conclui-se que o modelo dinâmico adotado pela neurociência contemporânea encontra paralelos em conceitos freudianos do final do século XIX.
\end{abstract}

Palavras-chave: Memória. Psicanálise. Neurociências.

Os neurocientistas e os psicólogos cognitivos têm se apoiado em descobertas neuropsicológicas sobre novos sistemas mnemônicos. Algumas dessas observações encontram paralelos em conceitos oriundos da teoria freudiana. Como exemplo, é possível citar as aproximações entre memória implícita e a noção de inconsciente proposta pela neurociência cognitiva. Embora o inconsciente cognitivo seja

1 Trabalho realizado no período de vigência da bolsa de Pós-Doutoramento de Josiane Cristina Bocchi, FAPESP (2009/54555-8). 
diferente do inconsciente psicanalítico, pelo menos em determinadas implicações que esse último possui, a distinção entre memória implícita e memória explícita foi apontada como um primeiro indício biológico da existência de uma vida psíquica inconsciente:"Na memória implícita, então, temos um exemplo biológico de um componente da vida mental inconsciente" (Kandel, 2005, p. 70). Desde a década de 1990, alguns fenômenos emocionais foram reinterpretados pelas neurociências sob a ótica da memória implícita, tais como o sentimento de constância do self, o reconhecimento das sensações corporais, das vozes familiares e até mesmo certos aprendizados de teor social. Acredita-se que essa memória seja crítica para o desenvolvimento das primeiras relações de objeto, conforme descritas pela psicanálise, pois ela teria um papel significativo em diversos aprendizados afetivos fundamentais (Clyman, 1991; Imbasciati, 2003). Assim, é provável que a retomada da memória pelas neurociências, como um fenômeno cognitivo que também pode ser estudado sob o ponto de vista das emoções, sinalize uma ampliação na concepção do tema, no sentido de uma visão mais psicodinâmica e, principalmente, que vai ao encontro de alguns pressupostos da teoria da memória em Freud. O presente trabalho apresentará, em um primeiro momento, as ideias acerca da neurobiologia da memória presentes na obra Projeto para uma psicologia científica (Freud, 1950/1976) de Freud, para em seguida analisar se, e, em caso afirmativo, como, algumas questões abordadas pelo autor são retomadas pela neurociência moderna.

\section{O Projeto para uma psicologia científica (1950/1976): uma teoria freudiana sobre a memória}

Embora escrito em 1895, o Projeto (1950/1976), por razões desconhecidas, é uma obra apenas publicada postumamente. Seu objetivo principal é descrever o funcionamento do aparelho psíquico em termos neuronais. Embora o neurônio já houvesse sido observado e descrito, com o auxílio do microscópio e de técnicas de marcação histológica como a de Nissl e a de Golgi ${ }^{2}$ poucos anos antes, seu mecanismo de funcionamento ainda era objeto de grande discussão. Freud era defensor da "Doutrina Neuronal" proposta pelo histologista espanhol Santiago Ramón y Cajal (1852-1934) (ver Centonze, Siracusano, Calabresi, \& Bernardi, 2004), que argumentava que as células nervosas comunicavam-se por meio de contato e não por continuidade (visão defendida por Golgi). Partindo de um modelo de neurônio que se comporta segundo a "Doupectivamente, que foram contemporâneos de Freud (Bear, Connors, \& Paradiso, 2002). 
trina Neuronal', Freud antevê o que será descrito pelo neurofisiologista inglês Charles S. Sherrington, dois anos depois, como sinapse (Pribram \& Gill, 1976). Um neurônio, de acordo com o Projeto (Freud, 1950/1976), comunica-se com outras células através das chamadas "barreiras de contato", liberando quantidades $(\mathrm{Q})$ de energia. Essa noção, embora criticada no passado (para uma discussão, ver Pribram \& Gill, 1976) por ser antiquada, relacionada a uma concepção hidrodinâmica da comunicação neural, resguarda uma clara semelhança com o que atualmente sabe-se acerca do mecanismo de propagação do impulso nervoso. Na verdade, segundo Pribram e Gill (1976), não é possível sustentar que Freud estava desenvolvendo um modelo hidrodinâmico:

As medições neuroelétricas de potenciais eletrotônicos e impulsos nervosos propagados eram não só um lugar-comum em 1895, mas também suficientemente recentes para empolgar a imaginação dos neurocientistas da época. Assim, Pflüger, um dos patrocinadores de Freud, publicou uma monografia sobre potenciais eletrotônicos em 1859. Por que motivo, então, Freud não identificou claramente uma quantidade de excitação neural com as suas manifestações elétricas? Justamente pela mesma razão que escrevemos hoje "com as suas manifestações elétricas". A propriedade básica do "movimento neuronal" (energia em movimento era uma expressão popular entre fisicistas) é neuroquímica e, em 1895, a neuroquímica da hiperpolarização e despolarização, e as características de membrana que dão origem a um impulso nervoso propagado estavam em sua infância. Assim, a natureza neuroquímica de $Q$ não podia ser descrita, apenas a sua manifestação em atividade elétrica. (p. 26)

Portanto, é possível entender $\mathrm{Q}$ não como quantidade de fluido, mas como quantidade física e química de energia. Nesse sentido, Qn (quantidade neuronal) seria sua manifestação neuroelétrica (ou neuroquímica). Ou seja, o que se tem aqui nada mais é do que "uma definição biológica do conceito de energia que pode ser significativamente ligada à neurofisiologia moderna" (Pribram \& Gill, p. 28).

É com base na noção de neurônio, segundo os pressupostos da "Doutrina Neuronal,"e quantidade (Q), não entendida segundo o modelo hidrodinâmico, mas sim físico-químico, que Freud (1950/1976) irá descrever no Projeto o funcionamento do aparelho psíquico em termos fisiológicos e, também, patológicos, já que, para Freud, a observação clínica de patologias permitia uma clara constatação da característica quantitativa dos processos psíquicos, ou seja, no adoecimento esses processos emergem mais intensamente, como ocorre na histeria.

Para Freud, um sistema nervoso primitivo funcionaria segundo o que ele chama de "princípio da inércia". Esse é um princípio que fundamenta todo o movimento reflexo. Um organismo primitivo recepcionaria $\mathrm{Q}$ ambiental e a eliminaria através de mecanismos musculares, conser- 
vando-se, portanto, sem estímulo (daí a ideia da inércia). A eliminação seria assim a função primária do sistema nervoso. Já os caminhos de eliminação de Qn, que se tornam possíveis pela função primária, Freud irá chamar de função secundária.

Entretanto, se um organismo primitivo funciona segundo o princípio da inércia, com o aumento da complexidade do organismo, o sistema nervoso passa a receber estímulos endógenos, que determinam as necessidades orgânicas (fome, respiração, sexualidade são os exemplos utilizados por Freud). Desses estímulos, não é possível escapar:"Eles só cessam sob condições determinadas que têm que ser realizadas no mundo externo." (Freud, 1950/1976, p. 176). Para Freud (1950/1976), estas $\mathrm{Q}$ endógenas impulsionam o funcionamento do aparelho psíquico (e é disso que trata, na linguagem do Projeto (1950/1976), o conceito de "pulsão"). Já as ações, responsáveis pela interrupção da estimulação, são chamadas de específicas.

Ora, para que as ações específicas possam ser realizadas é necessário o armazenamento de determinada quantidade neuronal (Qn). O termo alemão para essa acumulação (ou armazenamento) de Qn é Bezetzung (em inglês, catexe, ou catexia, em português) ${ }^{3}$. Por outro lado, Freud argumenta também que Qn deve ser mantida no menor nível possível, para que o organismo possa defender-se contra possíveis elevações das $\mathrm{Q}$ ambientais. Em outras palavras, Qn deve manter-se constante. O que ocorre, portanto, em um sistema nervoso complexo é um abandono da inércia em prol da constância.

Logicamente, para que determinada Qn possa ser conservada devem existir mecanismos que possibilitem essa retenção. Para explicar esse processo de ocupação neuronal por $Q$, Freud argumenta que existem resistências opostas à eliminação de Qn, que ele irá chamar de "barreiras de contato".

A partir daí Freud propõe a ideia de existência de dois agrupamentos neuronais: os neurônios $\Phi$, que nada mais seriam do que células perceptivas, em contato direto com o ambiente externo ao organismo, e que portanto seriam continuamente bombardeados por grandes intensidades de Q; e os neurônios $\Psi$, células recordativas, que não estabeleceriam contato direto com o mundo externo e, por isso mesmo, receberiam $Q$ de grandezas menores. Tendo em vista a intensidade de $Q$ recebida, Freud dirá também que os neurônios $\Phi$ são células "permeáveis" $(Q$ recebida, em função da sua grandeza, não permanece retida). Já os neurônios $\Psi$ seriam "impermeáveis". Ou seja, por receberem Q de grandezas menores, não conseguiriam eliminá-las totalmente, dada a existência das barreiras de contato (resistências opostas à eliminação de Qn).

3 Utilizando, entretanto, uma linguagem neurobiológica mais corrente, seria possível afirmar que um neurônio "ocupado" apresenta um "potencial eletroquímico" de determinada magnitude (Pribram \& Gill, 1976). 
Freud propõe ainda que os neurônios $\Psi$ poderiam ser subdivididos em dois agrupamentos: os neurônios do manto, que recebem Qn oriunda dos neurônios $\Phi$, e os neurônios do núcleo, que receberiam Qn de origem endógena. Esses últimos só seriam ativados com o aumento dos estímulos, gerados pelo próprio organismo. Ou seja, para que a Qn retida pelos neurônios $\Psi$ do núcleo fosse capaz de se contrapor à resistência oferecida pelas barreiras de contato, deveria haver somação de estímulos endógenos.

O sistema $\Psi$, composto por neurônios "impermeáveis", responderia, segundo Freud, pela memória e pelos processos psíquicos em geral: um aumento da ocupação neuronal (Bezetzung) em ambos os lados de uma barreira de contato (o que Freud irá chamar de Lei da Associação por Simultaneidade) levaria à facilitação (em alemão, Bahnung) de uma barreira de contato, e, desse modo, passagem de Qn para outro local do sistema nervoso.

As ideias expostas acima permitem a elaboração de uma teoria da memória que em muito se assemelha ao que tem sido proposto pela neurofisiologia moderna. O processo subjacente à formação de memórias é decorrente da facilitação das "barreiras de contato" entre os neurônios e, portanto, de um aumento da comunicação neuronal, em função de um aumento na liberação de Qn. Tem-se aqui algo próximo ao conceito de sinapse proposto em 1897 por Sherrington. Em termos neuronais, acredita-se hoje que é justamente o fortalecimento do contato sináptico entre neurônios que subjaz aos processos de aprendizado e memória. É disso que trata a noção de potenciação de longa duração, ou LTP, do inglês Long Term Potentiation ${ }^{4}$. A potenciação de longa duração é uma forma de neuroplasticidade, sendo que a única condição necessária para que ela ocorra é que um segundo estímulo seja aplicado ao neurônio quando este ainda se encontra em processo de despolarização (a seletividade da mudança, conforme mencionado abaixo, é uma das propriedades da LTP).Também para Freud:"uma Q $\eta$ de um neurônio passa mais facilmente para um [neurônio] ocupado do que para um desocupado" (essa é a Lei da Associação por Simultaneidade, já mencionada anteriormente) (Freud, 1950/1976, p. 364), ou seja, quando dois neurônios são ocupados ao mesmo tempo, a comunicação neuronal é mais efetiva. Isso significa dizer, nos termos encontrados no Projeto (1950/1976), que, com o aprendizado, decorrente de um aumento de $\mathrm{Q}$ (de origem endógena ou exógena), o sistema nervoso vai sendo moldado, passando, a partir daí, a funcionar de uma maneira específica.

Todos os processos mencionados até aqui independem do acesso à consciência do sujeito. São processos neurônicos que existem, portan-

4 Long Term Potentiation, ou Potenciação de Longa Duração, pode ser definida como o fortalecimento do contato sináptico entre neurônios, resultante da estimulação repetida (Izquierdo et al., 2008). 
to, sem que necessariamente se tornem conscientes. A consciência, dirá Freud, atribui aos processos psíquicos o que se chama de qualidade, e que se encontra a critério de um terceiro sistema neuronal proposto pelo autor, o sistema $\omega$. Esse sistema, movido por $\mathrm{Q}$ ainda menores do que o sistema $\Psi$, detectaria as diferenças nos períodos de excitação, que já teriam seu início, segundo Freud, nos próprios órgãos dos sentidos, os quais funcionariam como crivos, só permitindo a passagem de estímulos com determinados períodos. Os diferentes períodos detectados seriam assim transferidos de $\Phi$ para $\Psi$ e daí para $\omega$, produzindo, nesse último agrupamento neuronal, sensações conscientes de qualidade, de prazer e desprazer. Para Freud, portanto, consciência nada mais é do que a parte subjetiva dos processos fisiológicos. Uma ocupação forte de $\omega$ resultaria em desprazer, enquanto uma ocupação fraca resultaria em prazer.

A partir da descrição do funcionamento dos três agrupamentos neuronais propostos $(\Phi, \Psi$ e $\omega)$, Freud irá discorrer acerca do desenvolvimento do aparelho psíquico. De acordo com o princípio da constância, a ocupação dos neurônios $\Psi$ pelas Qs endógenas leva a um esforço de eliminação. Como é impossível a fuga desses estímulos, é necessário que o organismo intervenha sobre o meio ambiente para que a estimulação seja interrompida (realizando uma ação específica). Entretanto, a princípio, o organismo humano é incapaz de, por si só, intervir no ambiente externo. A criança necessita de ajuda externa. A comunicação, portanto, é de extrema importância para que o organismo possa interromper a estimulação (função secundária). Se um indivíduo auxilia outro imaturo na realização desta ação específica sobre o mundo externo, os estímulos endógenos são interrompidos e tem-se o que Freud irá chamar de "vivência de satisfação". Essa vivência tem consequências decisivas para o desenvolvimento funcional do indivíduo. Quando ela ocorre, três coisas se passam no sistema $\Psi: 1$ ) interrompe-se a estimulação que produziria desprazer em $\omega ; 2$ ) os neurônios $\Psi$ do manto são ocupados com a percepção do objeto que levou à interrupção da estimulação;3) outros locais do manto recebem as mensagens de eliminação, em função do movimento reflexo que se segue à ação específica ${ }^{5}$. Entre essas ocupações e os neurônios $\Psi$ do núcleo formam-se facilitações.

Ao contrário da vivência de satisfação, a dor produz em $\Psi$ uma forte ocupação, sentida como desprazer em $\omega$, levando a uma inclinação para a eliminação e a uma facilitação entre essa e a imagem recordativa do objeto que gerou a dor. De tal maneira que, se a imagem do objeto for novamente ocupada por uma nova percepção, se gera um estado não doloroso, mas similar ao estado de dor. Essa reprodução da vivência de dor, Freud irá chamar de "afeto". A reprodução implica na ocupação de

5 É possível utilizar 0 exemplo de uma criança faminta, que chora, comunicando-se dessa forma com a mãe, que a ampara, dando-lhe o seio. A visão do seio ocupa neurônios $\psi$ do manto, iniciando o movimento reflexo de suçãa que, segundo Freud, acarreta novas estimulações sensoriais, resultando em uma imagem motora em $\psi$. 
neurônios $\Psi$ (trata-se de uma memória). Com a ocupação desses neurônios, diz Freud, desprazer é liberado do interior do corpo. Com isso, Freud introduz a ideia de neurônios secretores, localizados no núcleo de $\Psi$, que, quando excitados pela ocupação recordativa, gerariam $Q$, ativando ainda mais os neurônios $\Psi$. Esses neurônios secretores, também chamados de "neurônios-chave", só seriam ativados a partir de um determinado nível de excitação, de acordo com as facilitações deixadas pela vivência de dor.

Enquanto a vivência de dor pode gerar afetos, a vivência de satisfação, segundo Freud, pode gerar os chamados "estados desiderativos". Esses últimos são resultantes da atração pelo objeto de desejo, pela sua recordação, enquanto da vivência de dor resulta uma repulsa a manter ocupada a imagem hostil. Ambos os estados deixam atrás de si, dirá Freud, motivos do tipo compulsivo, a atração desiderativa primária (alucinação) e a defesa primária, que receberão o nome de processos primários. A atração desiderativa é explicada em função da facilitação que ocorre entre os neurônios nucleares e do manto (ver acima). Já a defesa primária é explicada como a não ocupação de neurônios associados à vivência de dor.

É a partir daí que o Freud do Projeto (1950/1976) introduz o conceito de "Eu" (ou Ego). Tanto a atração desiderativa quanto a defesa primária levam a certa organização de $\Psi$ (tendo em vista que trilhas são formadas, em função da facilitação de "barreiras de contato"). 0 "Eu" freudiano é, assim, fruto da organização de $\Psi$, e é composto, segundo o autor, por uma parte permanente e uma parte variável. A parte permanente corresponde à Qn necessária para a realização da ação específica (retida nos neurônios $\Psi$ ). Já a parte variável corresponde às diversas Qn que ocupam neurônios $\Psi$ e que são eliminadas. A isso segue-se a observação de que o curso de uma determinada Qn pode ser influenciado pela ocupação de um neurônio vizinho (ou como Freud dirá, "pela ocupação lateral"). Portanto, para Freud, se existe um "Eu", sua função seria a de inibir (ou ligar, o termo alemão aqui adotado é Bindung) Q livre, pela ocupação de neurônios vizinhos (em alemão, Seitenbesetzung). Em outras palavras, a função do "Eu" seria a de inibir processos primários, transformando-os em algo que Freud chamará de processo secundário (e que seria equivalente, nesse texto, à atividade do pensamento). $\mathrm{E}$ isso seria indubitavelmente vantajoso para $\Psi$. Pois, caso contrário, o "Eu" em $\Psi$ sofreria desamparo e dano. Desamparo tendo em vista que a recordação do objeto amigável não gera satisfação, já que o objeto não possui existência real. No segundo caso, a recordação da imagem hostil geraria defesa excessiva ou patológica, que Freud irá chamar de repressão.

A facilitação das barreiras de contato é, portanto, largamente influenciada por processos emocionais, conforme ilustrado na segunda parte do Projeto (Freud, 1950/1976), a partir da exposição do caso Emma. O quadro clínico analisado, no texto, é a histeria. Freud argumenta que os histéricos encontram-se submetidos a ideias intensas, como em uma 
compulsão. Essas ideias apresentam consequências importantes (Freud menciona liberação afetiva, inervações motoras, impedimentos) e não são plenamente compreendidas pelo sujeito. E é nisso que uma compulsão histérica difere de uma ideia copiosamente intensa, encontrada em um indivíduo não histérico: a compulsão histérica é incompreensível, insolúvel pelo trabalho pensante e incongruente. $E$ isso se dá porque, à semelhança do que ocorre na vivência de dor (defesa primária), o histérico tende, a todo custo, a evitar a ocupação da imagem recordativa hostil. Para isso, $Q$ retirada de uma ideia qualquer ( $B$, por exemplo) é transferida para outra (A). E é isso que Freud irá chamar de deslocamento. Tem-se, assim, uma formação de símbolo. O que difere, entretanto, a compulsão histérica de uma defesa normal é que, no primeiro caso, se tem uma resistência extraordinariamente grande à ocupação de B. A formação de símbolo, na defesa patológica, encontra-se muito consolidada, ultrapassando o observado com a defesa normal.

Para ilustrar suas observações, Freud recorre ao relato de um caso clínico. O caso relatado é o de Emma, uma jovem que se encontra sob uma compulsão: a de não poder ir sozinha a uma loja. Para fundamentar sua compulsão, Emma relata o seguinte episódio: quando tinha 12 anos, foi a uma loja sozinha comprar algo. Dois balconistas conversavam e riam entre si. Tomada de terror, Emma foge. Recorda-se também de ter acreditado, na ocasião, que riam do seu vestido e que um dos balconistas lhe agradara sexualmente.

Entretanto, suas explicações não justificam seu medo de ir sozinha a lojas, por vários motivos: 1) muito tempo se passou, desde o episódio e o desenvolvimento da compulsão; 2) suas vestimentas em nada se alteram, caso vá sozinha ou acompanhada a uma loja; 3) é incompreensível que mesmo a companhia de uma criança faça-lhe sentir-se segura; 4) relatar que tenha gostado de um dos balconistas parece incompatível com o restante da história e isso também não seria modificado se estivesse acompanhada. Logo, diz Freud, as recordações de Emma não explicam nem a compulsão nem determinam o sintoma.

A partir de uma investigação posterior, Freud descobre que, anos antes, quando Emma tinha 8 anos de idade, ela havia, por duas ocasiões simultâneas, ido sozinha a uma mercearia comprar doces. Na primeira ocasião, o merceeiro, rindo, beliscou-lhe os genitais por baixo do vestido. Apesar disso, Emma retorna uma segunda vez. Ao relatar essa lembrança, recrimina-se por ter ido uma segunda vez.

Ao analisar os dois episódios conjuntamente, e a partir das ideias de deslocamento e formação de símbolo, é possível entender o episódio 1. Em ambos os casos, há o relato do riso (o riso dos balconistas desperta a lembrança do riso do merceeiro) e do "estar sozinha". A diferença é que, entre o episódio com o merceeiro e o episódio da loja, Emma havia entrado na puberdade. De acordo, portanto, com o Freud do Proje- 
to (1950/1976), a excitação sexual precoce gera uma soma significativa de Qn. Entretanto, sem maturidade sexual, não há compreensão do fato ocorrido. Logo, a Qn gerada permanece livre, isto é, não ligada a representações. Com o ingresso na puberdade e o episódio com os balconistas, ocorre a recordação do episódio original.

Um histérico, portanto, para o Freud do Projeto (1950/1976), é um indivíduo que foi sexualmente excitado precocemente. Essa excitação precoce levaria a um aumento de Qn, que não teria como ser eliminada através de uma ação específica (cópula), tendo em vista a imaturidade sexual do sujeito. Esse fluxo de Qn alteraria o curso normal do pensar, levando a certa organização de $\Psi$, e consequentemente do "Eu", que não inibiria ou ligaria de maneira adequada Qn, transformando-a em processo secundário. Com a inibição da atividade do pensamento, caminhos deixam de ser trilhados, fazendo com que o indivíduo se esqueça (a repressão incorre em uma alteração do mecanismo de Bahnung, portanto, não há memória consciente). Segundo, não se elimina quantidade de maneira apropriada. Portanto, o processo afetivo é muito semelhante ao processo primário não inibido pelo "Eu" ativo.

\section{O caso H.M., a memória implícita e a noção de inconsciente}

Em boa parte do século XIX, a memória fora estudada como uma função cognitiva ligada à captação e armazenamento dos traços mnêmicos. O cheiro das madeleines do personagem de Marcel Proust (e tudo o que elas evocam), a lembrança do tanino de um bom vinho e mesmo a imagem do rosto de alguém dependeriam desse repertório autobiográfico de impressões sensoriais que corresponderiam à imagem dos objetos percebidos. Essa concepção da memória supõe a existência de traços fixos e, portanto, de uma aparente exatidão e permanência da memória (Rosenfield, 1994).

De fato, a memória como armazenamento tem afinidades conceituais com as teses que sustentaram a doutrina da localização de funções no século XIX, mais conhecida como "localizacionismo" ${ }^{\circ}$, e que fora o ponto de apoio dos estudos sobre um grupo específico de distúrbios de linguagem, as afasias. Esses estudos pressupunham que a autonomia funcional dos diferentes centros cerebrais da linguagem estava assentada na especialização dos centros mnemônicos, como "centros visuais" para as palavras e outros centros para processar imagens acústicas e motoras, e assim por diante (Rosenfield, 1994, pp. 67-68). A aquisição dessas

60 localizacionismo é uma doutrina que possui como fundamento básico a discriminação de estruturas encefálicas responsáveis por funções e subfunções específicas (por exemplo, uma função que diz respeito à linguagem e uma subfunção que processa verbos irregulares) (Maciel, 1998). 
imagens ocuparia áreas corticais originalmente desprovidas de função e seu correlato físico seria um engrama contido em uma célula do córtex, revelando outro princípio fundamental da doutrina localizacionista, qual seja, de uma concepção isomórfica e simétrica da relação mente-cérebro (Caropreso \& Simanke, 2011). Os diagramas dos distúrbios de linguagem tinham como um dos pontos centrais a teoria do engrama e o armazenamento de conteúdos mentais no cérebro, supondo aí elementos psíquicos que, de uma forma ou de outra, estariam armazenados em células nervosas.

O localizacionismo surge com o advento da frenologia, que dividia faculdades mentais superiores de acordo com um mapeamento morfológico do crânio ${ }^{7}$. Já a concepção tradicional da memória como "registro-conservação-e-evocação" remonta, em essência, à concepção filosófica da memória presente desde Aristóteles, que explica o fenômeno a partir do símile da marca do selo sobre a cera, como a impressão física dos traços cerebrais (logo, como engrama ou marca física).

Embora a concepção da memória como armazenamento fundamentasse grande parte dos estudos do século XIX, algumas formulações teóricas dessa época opunham-se ao ponto de vista predominante do engrama. Em particular, cabe mencionar, para a finalidade deste trabalho, a concepção psicodinâmica de Freud.

Com a virada do século XX, e portanto poucos anos após a publicação do Projeto (1950/1976), alguns estudos começam sistematicamente a questionar a existência de engramas. Como exemplo, é possível citar aqui os experimentos inicialmente realizados por Karl Lashley, com animais que apresentavam lesões corticais. Lashley foi capaz de demonstrar que embora a memória de uma determinada tarefa pudesse ser afetada pelas lesões, a retirada de nenhuma área cortical específica fazia com que a memória da tarefa desaparecesse. Ou seja, a partir desses resultados, o autor concluiu que nada podia ser afirmado com relação à natureza do engrama (Finger, 1994).

Sabe-se, hoje, que o grande erro de Lashley (e de alguns de seus antecessores) foi acreditar na existência de um sistema de memória único. Atualmente, a existência de múltiplos sistemas é largamente aceita (Clyman, 1991; Kandel, 2005; Squire \& Zola-Morgan, 1996). Cada um desses sistemas relaciona-se ao processamento de formas de aprendizado e memória distintas e encontra-se relacionado à atividade conjunta de diferentes estruturas encefálicas (ver Tabela 1), o que, portanto, também afasta a concepção atual da doutrina localizacionista. Por uma singular ironia, a descoberta de novos sistemas de memórias, responsável por impulsionar os estudos neurobiológicos na área, se deu a partir do caso clí-

7 Para uma apresentação sistemática sobre os princípios da frenologia de Gall e Spurzheim, bem como sua repercussão em diferentes disciplinas do século XIX, e em particular nos estudos sobre a localização funções mentais no cérebro, ver Clarke \& Jacyna (1987, pp. 240-243). 
nico de um indivíduo que justamente perdeu a capacidade de ter novas memórias. O que a neurociência conhece atualmente sobre o modo pelo qual o cérebro registra novos acontecimentos surge a partir do caso H.M. A história de Henry Gustav Molaison (H. M.), cujo nome verdadeiro só foi revelado após sua morte em 2008, é descrita, pela primeira vez, em um artigo de William Scoville e Brenda Milner, de 1957. Posteriormente, H.M. se tornou muito conhecido pela comunidade acadêmica como o paciente que mais contribuiu para a compreensão da memória; submetendo-se a centenas de estudos. O que tornou seu caso tão peculiar foi que, mesmo apresentando uma severa amnésia anterógrada, ele não apresentava sintomas psiquiátricos e manteve as funções intelectuais preservadas (inclusive, QI elevado):“Ele era o que chamávamos de um caso de amnésia pura" (Corkin, 2009).

H.M. adquiriu essa condição após uma neurocirurgia realizada em 1953 por Scoville, como última tentativa para estabilizar um quadro epiléptico resistente à medicação e que acarretava severos prejuízos funcionais. Devido à frequência diária das crises convulsivas, H. M. foi levado a interromper seus estudos e posteriormente abandonar seu emprego. A cirurgia de ressecção bilateral do lobo temporal envolveu a retirada de dois terços do hipocampo, e de algumas estruturas adjacentes, e foi realizada quando $\mathrm{H}$. M. contava com 27 anos de idade. $\mathrm{O}$ procedimento cirúrgico foi bem-sucedido, reduzindo significativamente as crises convulsivas. Por outro lado, H. M. passou a apresentar, a partir daí, um importante prejuízo em suas funções mnemônicas: tornou-se incapaz de reter novas informações por um período superior a 15 minutos. Suas memórias da infância e juventude, por outro lado, mantiveram-se preservadas com riqueza de detalhes, com exceção das memórias episódicas (ou seja, ele não podia dizer o momento e o lugar em que os acontecimentos se deram). Em outras palavras, H. M. passou a apresentar um severo quadro de amnésia anterógrada (referente a eventos que ocorreram após a cirurgia), porém um quadro brando de amnésia retrógrada (referente a eventos que ocorreram antes da cirurgia). 
Tabela 1

Sistemas de memória e substratos neurais relacionados.

\begin{tabular}{|c|c|}
\hline Memória & Substrato Neural \\
\hline Memória a curto prazo (ou de trabalho) & Córtex pré-frontal \\
\hline Memória explícita ou declarativa & Lobo temporal medial, diencéfalo \\
\hline Priming & Córtex ocipital, temporal e frontal \\
\hline Aprendizado de tarefas motoras & Estriado \\
\hline Condicionamento clássico & Cerebelo \\
\hline Condicionamento emocional & Amígdala \\
\hline
\end{tabular}

Adaptado de Viana (1999).

H. M. foi acompanhado por mais de 50 anos pela neuropsicóloga norte-americana Brenda Milner e por Suzanne Corkin, orientanda de MiIner. Com a ajuda de testes neuropsicológicos, observou-se que ele era capaz de adquirir novas memórias, embora "conscientemente" não fosse capaz de evocá-las. Em particular, H. M. aprendeu a executar determinadas tarefas motoras como, por exemplo, completar um desenho ou montar um quebra-cabeça. $O$ desempenho dele, nesses casos, melhorava gradualmente com a introdução, por parte do examinador, de pistas e informações prévias. Ou seja, em se tratando de tarefas motoras, H. M. apresentava uma melhora gradual que dependia do treino, da repetição. Por exemplo, em uma tarefa motora específica, pedia-se a H.M. que desenhasse um objeto olhando apenas para seu reflexo no espelho. Trata-se de uma tarefa que apresenta certo grau de dificuldade, mas que com o passar do tempo era realizada com destreza por H. M.

As investigações sobre a memória de H.M. representaram um avanço significativo nas pesquisas sobre a neurobiologia da memória. A primeira grande descoberta foi a de que haveria diferentes sistemas para o processamento das memórias de curto e longo prazo. Concluiu-se, desde então, que a (posteriormente denominada)"memória declarativa" dependia das operações de estruturas do lobo temporal, ausentes em H. M. Em segundo lugar, haveria ainda, pelo menos, um sistema mnemônico dedicado às tarefas motoras e sensoriais e o mais surpreendente: seu processamento se dava por vias independentes da consciência. Mais tarde, esse 
sistema mnemônico foi denominado memória implícita (ou não declarativa) por oposição à memória declarativa (ou explícita), essa última ligada às funções semânticas e autobiográficas (Milner, Squire, \& Kandel, 1998). A memória implícita englobaria diferentes tipos de memória, conforme ilustrado na tabela $1^{8}$.

Curiosamente, H. M. ainda reteve algumas poucas informações inéditas e que não requisitaram somente a memória implícita. Mesmo subestimando sua idade, ele reconhecia seu rosto no espelho (embora, naturalmente, houvesse mudado de feições com o passar dos anos). Aprendeu a associar o nome de Suzanne Corkin a sentimentos familiares, ela que continuou acompanhando-o mesmo depois que Brenda Milner se aposentou. Pôde construir uma representação mental da casa onde passou a morar após a intervenção cirúrgica e também a identificar o rosto de algumas pessoas famosas (que haviam se tornado conhecidas após a cirurgia). Esses aprendizados tinham em comum o fato de que haviam sido adquiridos ao longo de vários anos, o que significa que puderam ser constantemente atualizados. Em outras palavras, essas observações sugeriam que o processamento de conteúdos emocionais estava, em algum grau, preservado em H.M. Ou seja, das descobertas proporcionadas pela amnésia de H. M., abre-se um precedente inédito nas neurociências para uma aproximação bem estabelecida do ponto de vista experimental entre memória, inconsciente e afetividade.

Na verdade, é possível afirmar que o conceito de memória implícita é inseparável do conceito de inconsciente cognitivo (Kandel, 2005). Assim, é interessante identificar em que medida o inconsciente cognitivo se aproxima do inconsciente freudiano. ${ }^{9}$ Conforme mencionado, a teoria da memória elaborada pelo Freud do Projeto (1950/1976) trata de processos a princípio inconscientes e que, eventualmente, podem ganhar acesso à consciência. De fato, para Freud, a consciência nada mais é do que o lado subjetivo dos processos inconscientes. Em outras palavras, para Freud, a atividade mental é em si mesma inconsciente. Somente sob circunstâncias especiais um fenômeno psíquico qualquer ganha acesso à consciência. Na linguagem do Projeto (1950/1976), o sistema $\Psi$ é respon-

8 Como o priming (que se refere à influência que um evento antecedente exerce sobre o desempenho de um evento posterior), 0 aprendizado de tarefas motoras, 0 condicionamento clássico (que descreve os efeitos da associação estímulo condicionado - estímulo incondicionado sobre o aprendizado de uma resposta) e o condicionamento emocional (que descreve a influência de uma experiência perceptiva sobre uma resposta emocional).

9 Embora haja aproximações possíveis, algumas distinções necessitam ser traçadas entre os dois conceitos. Dentre as características que 0 diferenciam do inconsciente descrito pela neurobiologia estão, sobretudo, sua fundação na teoria sexual infantil e na noção de desejo; portanto, na sua dimensão pulsional e conflitiva. Para alguns autores, entretanto, é possível encontrar na obra de Freud diferentes definições de inconsciente (ver Kandel, 2005; Lyra, 2007), sendo que pelo menos uma delas, a ideia de inconsciente não reprimido, se aproxima do conceito adotado pelas neurociências. Essa é a visão apresentada neste trabalho. Para uma revisão sobre o conceito de inconsciente para Freud, ver Caropreso e Simanke (2011). 
sável pela memória (que, portanto, é também a princípio inconsciente, ou como propõe a neurociência contemporânea, "implícita") e por processos psíquicos em geral. Já o sistema $\omega$, que eventualmente receberia Qn a partir de $\Psi$, seria o detentor dos processos conscientes, atribuindo qualidade às vivências do sujeito, e assim estabelecendo uma distinção entre percepção alucinatória e percepção qualitativa da realidade. Essa distinção, por sua vez, só poderia ser realizada com sucesso havendo inibição efetiva, por parte do "Eu" ativo, de processos primários.

Por outro lado, também no Projeto, Freud (1950/1976) propõe a ideia, em particular em sua análise do caso Emma, de que ao longo do desenvolvimento do aparelho psíquico a repressão exerce um papel importante na determinação do inconsciente, impedindo o acesso à consciência de determinadas memórias carregadas de conteúdo emocional. Nesse sentido, é possível afirmar que o conceito de repressão encontra-se relacionado ao armazenamento de experiências em sistemas de memória explícita.Tem-se, também como resultado desse processo, uma noção de inconsciente (sob efeito da repressão) que exerce influência sobre a consciência e se manifesta através das livres associações, lapsos, sonhos, processos psicopatológicos.

Levando em consideração o exposto acima, e conforme já observado por alguns autores (Damásio, 1996; Kandel, 2005; Lyra, 2007; Semenza, 2001; Solms, 2000), talvez seja possível afirmar a existência na obra de Freud, desde o Projeto (1950/1976), de pelo menos dois tipos de inconsciente: o inconsciente reprimido e o inconsciente não reprimido. Esse último, nunca acessível à consciência, englobaria hábitos e habilidades motoras e perceptivas. De fato, ao descrever as três instâncias psíquicas (inconsciente, pré-consciente e consciente) na obra $A$ interpretação dos sonhos (1900/1976), Freud irá definir o inconsciente como o conjunto dos conteúdos não presentes no campo atual da consciência. Esses conteúdos podem ter sido conscientes, em algum momento, e ter sido reprimidos, fazendo parte, portanto, do que está sendo chamado de inconsciente-reprimido, ou podem ser genuinamente inconscientes (isto é, nunca antes reprimidos).

É possível estabelecer, assim, um paralelo importante entre esse sistema de memória de conteúdos inconscientes, não sujeito à ação da repressão, proposto por Freud, e a ideia de um sistema de memória implícita descrito pelas neurociências. Enquanto o inconsciente reprimido freudiano encontraria uma correspondência funcional nas estruturas da memória explícita, o inconsciente não reprimido encontraria na memória implícita sua própria organização autobiográfica. De fato, tem sido demonstrado a partir de estudos com ressonância magnética funcional (Anderson et al., 2004) que o fenômeno da repressão é acompanhado pela ativação do córtex pré-frontal ântero-lateral (envolvido na memória de trabalho) e pela inibição da atividade do hipocampo, uma estrutura 
integrante do lobo temporal medial (ver tabela 1), que funciona, segundo Izquierdo et al. (2008), como uma espécie de maestro da "orquestra" de áreas corticais envolvidas na evocação de memórias declarativas. Esse fenômeno se opõe ao caráter "desrepressivo" dos sonhos (descritos por Freud como processos primários, não sujeitos à ação da repressão). Em finais da década de 1990, Braun e colaboradores (1997) já haviam demonstrado, também a partir da utilização de técnicas de neuroimagem, que os sonhos (sono-REM) são acompanhados por um aumento da atividade do hipocampo e uma desativação do córtex pré-frontal.Talvez, portanto, o inconsciente não reprimido encontre nos sistemas responsáveis pela memória implícita - amígdala, áreas corticais associativas, estriado e cerebelo (ver Tabela 1) - sua própria organização.

\section{As ideias de Freud e as investigações neurocientíficas sobre a 'potenciação de longa duração'}

Ao mesmo tempo em que os estudos sobre a neuroanatomia dos sistemas de memória explícita e implícita ganhavam força a partir das observações provenientes do caso H. M., descobertas neurocientíficas realizadas por Kandel e colaboradores (ver Kandel \& Schwartz, 1982) impulsionavam o entendimento acerca da neuroquímica dos processos mnemônicos. Kandel, que ganhou o prêmio Nobel de Medicina e Fisiologia em 2000, inicia em meados do século XX alguns estudos com um comportamento reflexo presente em um molusco marinho, a aplísia. Esses animais possuem um sifão sobre suas brânquias. Ao simples toque mecânico, brânquias e sifão retraem-se, caracterizando um arco reflexo monossináptico: o reflexo de retirada das brânquias. Para estudar em termos neuroquímicos esse comportamento reflexo, Kandel implantou cirurgicamente eletrodos de registro no gânglio abdominal dos animais (espécie de sistema nervoso central das aplísias) e verificou o reflexo de retiradas das brânquias frente a dois estímulos isolados: um indolor, e outro doloroso. Em resposta ao primeiro, a aplísia progressivamente deixava de apresentar o reflexo de retirada das brânquias, apresentando habituação. Já em resposta ao segundo estímulo, a aplísia apresentava um aumento do comportamento reflexo, o que Kandel chamou de sensibilização.Tratava-se, pois, de duas formas de aprendizado bastante simples, do tipo não associativo. A partir de registros neuroquímicos, Kandel foi capaz de demonstrar que ambas as formas de aprendizado eram acompanhadas por alterações sinápticas: no primeiro caso (habituação), o neurônio sensorial proveniente da pele dos sifões, com a estimulação repetida, deixava de liberar neurotransmissor na fenda sináptica (provavelmente em função de uma inativação progressiva de canais de cálcio). No segun- 
do (sensibilização), o neurônio sensorial era sensibilizado, em função de contatos sinápticos estabelecidos com interneurônios ativados pelo estímulo doloroso. Havia assim maior liberação de neurotransmissor na fenda sináptica e uma maior ativação dos neurônios motores responsáveis pelo reflexo de retirada das brânquias. Posteriormente, Kandel também foi capaz de demonstrar que também em uma forma de aprendizado associativo, o condicionamento clássico, as alterações comportamentais eram acompanhadas por alterações sinápticas.

Aproximadamente na mesma época em que Kandel realizava seus estudos com invertebrados, dois pesquisadores noruegueses, Terje L $\Phi m \circ$ eTim Blis demonstravam que estímulos elétricos de alta frequência e curta duração (estímulos tetânicos), quando aplicados a células hipocampais de coelhos, acarretavam o fortalecimento duradouro de sinapses já existentes (LФmo \& Bliss, 1973). Esse fenômeno ficou conhecido como potenciação de longa duração (LTP, do inglês Long Term Potentiation). O único fator indispensável para a ocorrência de LTP era que um novo estímulo fosse aplicado à célula nervosa no momento em que essa se encontrava em processo de despolarização: "uma mudança ocorrerá somente se o neurônio recebe os inputs corretos simultaneamente. A sincronicidade aparece como um importante aspecto" (Hölscher, 2001, pp. 2-3, itálicos nossos). Haveria, assim, somação de potenciais excitatórios pós-sinápticos, induzindo à formação de LTP. Essa propriedade associativa dos neurônios tem ressonâncias com outro princípio teorizado por Freud para explicar a ação inibitória do "Eu" a partir de suas ocupações laterais. Ou seja, interessa saber como os caminhos excitatórios podem ser redirecionados no aparelho psíquico.Para tanto,conforme já mencionado, Freud postula a "Lei de Associação por Simultaneidade", que diz que a ocupação de dois neurônios ao mesmo tempo cria uma facilitação maior do que a ocupação de um, podendo, assim, alterar o curso da excitação (Freud, 1950/1976).

Portanto, as formulações freudianas do Projeto (1950/1976) apresentadas contemplam efetivamente uma seletividade da facilitação. Essa é impulsionada por um fator ontogenético e um fator filogenético, biológico: o primeiro corresponde à história das vivências do organismo e de suas experiências de contato com o mundo externo que foram forjando caminhos mais bem facilitados do que outros; o segundo fator diz respeito às restrições biológicas que inibiram as facilitações geradoras de desprazer quando no aparelho neuropsíquico vigoravam apenas os processos primários (o livre curso excitatório de Q), isto é, num momento em que o "Eu" não havia ainda sido formado no psiquismo ${ }^{10}$.

10 Se não há um “Eu” ativo, não há formação de processos secundários. Logo, não há memória explícita ou consciente. Há apenas, nesse momento, o inconsciente puro, não reprimido, noção essa que, como demonstrado, aproxima-se da ideia de existência de um sistema de memória implíito, conforme proposto pela neurociência moderna. 


\section{Conclusões}

É possível, então, falar de uma nova memória inaugurada pelas neurociências? A resposta é não do ponto de vista conceitual. A novidade está no fato de que o modelo mnemônico para estratégias afetivas e interpessoais inconscientes, proposto pela neurociência moderna, pode ser testado empiricamente. A memória é, assim, redescoberta pelas neurociências como uma importante via para entender os processos neuropsíquicos implícitos, isto é, não conscientes. Desse modo, é possível pensá-la como uma espécie de "via régia" do inconsciente cognitivo, assim como os sonhos foram a via real para o inconsciente psicanalítico em A interpretação dos sonhos (1900/1976).

Não é possível falar propriamente de uma nova memória do ponto de vista conceitual, pois uma concepção psicodinâmica sobre a memória remonta, sob muitos aspectos, à natureza criativa que a memória tem em Freud, na qual a fantasia inconsciente e o desejo são capazes de ressignificar vivências e de instaurar novos sentidos a partir da experiência passada. Existem aproximações entre aspectos da teoria da memória em Freud, a neurobiologia subjacente ao conceito de facilitação (Bahnung), a ideia de LTP e essa concepção dinâmica que desponta a partir de investigações neurocientíficas mais recentes, a fim de apontar a existência de uma mesma linha de pensamento sobre a memória, ligada à integração contínua de funções psíquicas e à experiência do seu uso. Ou seja, se hoje a memória é entendida sob um ponto de vista neurodinâmico, isso não foi inaugurado recentemente. A novidade encontra-se nas evidências científicas e experimentais que lhe dão respaldo, e que surpreendentemente corroboram algumas prerrogativas de Freud sobre o tema.

E Freud, ao que tudo indica, estava ciente das implicações da sua teoria psicodinâmica sobre a memória quando a formulou como uma função construída ao longo da história das vivências do aparelho psíquico. Através das vicissitudes do aparelho, a percepção e a memória são modificadas por novas representações trazidas pelas diferentes fases do desenvolvimento do indivíduo, o que imprime um modo particular de organização e de atualização dos traços mnêmicos. Na Carta 52 (1896/1986), o autor se refere à memória como um "rearranjo" entre os processos: "o material presente sob a forma de traços mnêmicos fica sujeito, de tempos em tempos, a um rearranjo, de acordo com as novas circunstâncias - a uma retranscrição" (p. 208). Empolgado, anuncia a Fliess essa grande novidade:"o que há de essencialmente novo em minha teoria é a tese de que a memória não se faz presente de uma só vez, e sim ao longo de diversas vezes, e que é registrada em vários tipos de indicação" (Freud, 1896/1986, p. 208). 


\section{Freud, neurosciences and a theory of memory}

Abstract: Previous evidences suggest that psychoanalytical concepts and recent neurobiological findings may complement each other, contributing to the better understanding of certain psychobiological processes. These evidences also indicate the possibility of interpretation of psychoanalytical concepts from a neurocientific perspective. This study investigates possible points of similarity between a theory of memory proposed by Freud and ideas formulated during the second half of the 20th century, on the basis of clinical (the case of patient H.M.) and experimental (the concept of Long Term Potentiation, LTP) findings. For that, at first, Freudian ideas regarding mnemonic processes underlying the construction of the Ego, found in the Project for a scientific psychology (1950/1976), are presented. Subsequently, studies which gave rise to a neurobiological theory of memory are analyzed. It is concluded that the dynamic model adopted by contemporary neuroscience shares important similarities with Freudian concepts proposed at the end of the 19th century.

Keywords: Memory. Psychoanalysis. Neurosciences.

\section{Freud, neurosciences et une théorie sur la mémoire}

Résumé: II y a études qui ont démontré que concepts psychanalytiques et les recherches neuroscientifiques peuvent être complémentaires et contribuent pour la compréhension de certains processus psicobiologiques. Ces études suggèrent aussi la possibilité d'interprétation des concepts psychanalytiques à partir de son rapprochement aux neurosciences. Cet article avalise les liens possibles entre une théorie sur la mémoire proposée par Freud et des conceptions neuroscientifiques de la seconde moitié du XXe siècle, basé sur observations cliniques (cas du patient $\mathrm{HM}$ ) et expérimentales (concept de potentialisation à long terme, LTP). Premier seront présentées les idées de Freud sur des processus mnémoniques qui soutiennent la construction du Moi chez son ouvrage Esquisse d'une psychologie scientifique (1950/1976). Ensuite, seront analysées les études qui apportent la construction de une théorie neurobiologique sur la mémoire. On conclut que le modèle dynamique adoptée par la neuroscience présents similitudes à des concepts freudiens de la fin du XIXe siècle.

Mots-clés: Mémoire. Psychanalyse. Neurosciences. 


\section{Freud, las neurociencias y una teoría de la memoria}

Resumen: Estudios tienen demostrado que conceptos psicoanalíticos y descubiertas neurocientíficas recientes pueden ser complementarios, colaborando para la comprensión de ciertos procesos psicobiológicos. Estos estudios también sugieren la posibilidad de interpretación de los conceptos psicoanalíticos, a partir de su proximidad con las neurociencias. Este trabajo investiga relaciones entre una teoría acerca de la memoria propuesta por Freud y concepciones que surgen desde la segunda mitad del siglo XX, basándose en observaciones clínicas (caso del paciente H.M.) y experimentales (concepto de potenciación a largo plazo, LTP). Primero, se presentarán ideas de Freud acerca de los procesos mnemónicos que subyacen a la construcción de un Yo, contenidas en su Proyecto para una psicología científica (1950/1976). A seguir, se analizarán estudios que dieron subsidios para la construcción de una teoría neurobiológica de la memoria. Se concluye que el modelo dinámico adoptado por la neurociencia presenta similitudes con conceptos freudianos propuestos a finales del siglo XIX.

Palabras-clave: Memoria. Psicoanálisis. Neurociencias.

\section{Referências}

Anderson, M. C., Ochsner, K. N., Kuhl, B., Cooper, J., Robertson, E., Gabrieli, S. W., et al. (2004). Neural systems underlying the suppression of unwanted memories. Science, 303, 232-35.

Bear, M. F., Connors, B. W., \& Paradiso, M. A. (2002). Neurociências, desvendando o sistema nervoso. Porto Alegre: ArtMed.

Braun, A. R., Balkin, T. J., Wesensten, N. J., Carson, R. E., Varga, M., Baldwin, P., et al. (1997). Regional cerebral blood flow throughout the sleep-wake cycle. An H215O PET study. Brain, 120, 1173-97.

Caropreso, F., \& Simanke, R. T. (2011). Entre o corpo e a consciência: ensaios de interpretação da metapsicologia freudiana. São Carlos: EdUFSCar.

Centonze, D., Siracusano, A., Calabresi, P., \& Bernardi, G. (2004). The Project for a Scientific Psychology (1895): A Freudian anticipation of LTP-memory connection theory. Brain Research Reviews, 46, 310-31.

Clarke, E., \& Jacyna, L. S. (1987). Nineteenth-century origins of neuroscientific concepts. California: University of California Press. 
Clyman, R. B. (1991). The procedural organization of emotions: A contribution from cognitive science to the psychoanalytic theory of therapeutic. Journal of the American Psychoanalytic Association, 39S, 349-382.

Corkin, S. (2009, November 16 ). The man who couldn't remember [Interview of Suzanne Corkin conducted in February 2009 by Sarah Holt, producer of "How Memory Works," and edited by Susan K. Lewis] NOVAScience Now. Recuperado em 25 de agosto de 2011, de http://www.pbs.org/wgbh/nova/body/corkin-hmmemory.html

Damásio, A. R. (2000). O mistério da consciência. São Paulo: Companhia das Letras.

Finger, S. (1994). Origens of neurosciences. New York: Oxford.

Freud, S. (1976). A interpretação dos sonhos. In S. Freud, Edição standard brasileira das obras completas de Sigmund Freud (J. Salomão, trad., Vols. 4-5). Rio de Janeiro: Imago. (Trabalho original publicado em 1900)

Freud, S. (1976). Projeto para uma psicologia científica. In S. Freud, Edição standard brasileira das obras completas de Sigmund Freud (J. Salomão, trad., Vol. 1, pp. 381517). Rio de Janeiro: Imago. (Trabalho original publicado em 1950)

Freud, S. (1986). Carta 52. In J. M. Masson, A correspondência completa de Sigmund Freud para Wilhelm Fliess 1887-1904 (V. Ribeiro, trad.). Rio de Janeiro: Imago. (Trabalho original publicado em 1950)

Gabbi Jr., O. F. (2003). Notas a projeto de uma psicologia: as origens utilitaristas da psicanálise. Rio de Janeiro: Imago.

Hölscher, C. (2001). Introduction: Long-term potentiation as a model for memory mechanisms. In C. Hölscher, Neuronal mechanisms of memory formation: Concepts of long-term potentiation and beyond. Cambridge: University Press.

Imbasciati, A. (2003). Cognitive sciences and psychoanalysis: A possible convergence. Journal of the American Academy of Psychoanalysis, 31, 627-646.

Izquierdo, I., Cammarota, M., Silva, W. C., Bevilaqua, L. R. M., Rossato, J. I., Bonini, J. S., et al. (2008). The evidence for hippocampal long-term potentiation as a basis for memory of simple tasks. Anais da Academia Brasileira de Ciências, 80(1), 115-127.

Kandel, E. R. (2005). Biology and the future of psychoanalysis: A new intellectual framework for psychiatry revisited. In E. R. Kandel, Psychiatry, psychoanalysis and the new biology of mind (pp. 63-106). Washington, DC: American Psychiatric. 
Kandel, E. R. (2007). À la recherche de la mémoire: Une nouvelle théorie de l'esprit (M. Filoche, trad.). Paris: Odile Jacob.

Kandel, E. R., \& Schwarts, J. H. (1982). Molecular biology of learning: Modulation of transmitter release. Science, 218, 433-443.

LФmo, T., \& Bliss, T. (1973). Long-lasting potentiation of synaptic transmission in the dentate area of the anaesthesised rabbit following stimulation of the perforant path. Journal of Physiology, 232, 331-356.

Lyra, C. E. S. (2007). O inconsciente e a consciência: da psicanálise à neurociência. Psicologia USP, 18(3), 55-73.

Maciel, L. M. A. (1998). Proposta do conceito de dinâmica ontogenética contextual aproximando o "Projeto" de Freud dos impasses da psicopatologia contemporânea. Tese de Doutorado, Instituto de Psicologia, Universidade de São Paulo.

Milner, B., Squire, L., \& Kandel, E. R. (1998). Cognitive neuroscience and the study of memory. Neuron Review, 20, 445-468.

Pribram, K., \& Gill, M. (1976). O Projeto de Freud: um exame crítico. São Paulo: Cultrix.

Rosenfield, I. (1994). A invenção da memória (V. Ribeiro, trad.). Rio de Janeiro: Nova Fronteira.

Semenza, C. (2001). Psychoanalysis and cognitive neuropsychology. Neuropsychoanalysis, 3, 3-10.

Squire, L. R., \& Zola-Morgan, S. (1996). Isquemic brain damage and memory impairment : A commentary. Hippocampus, 6, 546-542.

Solms, M. (2000). A psychoanalytic perspective on confabulation. NeuroPsychoanalysis, 2, 133-38.

Viana, M. B. (1999). Amnésia. In F. G. Graeff \& M. L. Brandão, Neurobiologia das doenças mentais (pp. 199-221). São Paulo: Lemos. 
Josiane Cristina Bocchi, Departamento de Psicologia, Universidade Federal de São Carlos (UFSCar). Endereço para correspondência: Rodovia Washington Luis, km 235, São Carlos-SP, Caixa Postal 676, CEP: 13.565-905. Endereço eletrônico: b.josiane@ gmail.com

Milena de Barros Viana, Departamento de Biociências, Universidade Federal de São Paulo (UNIFESP), Campus Baixada Santista. Endereço para correspondência: Av. Ana Costa, 95, 11060-001, Santos - SP.Endereço eletrônico: milenabv@gmail.com

Recebido: 02/12/2011

Aceito: $27 / 07 / 2012$ 